\title{
Implications of the Calman report on child health and paediatrics
}

\author{
David W A Milligan, David M B Hall
}

\begin{abstract}
Background
Medical education has come under increasing scrutiny over the last 10 years. A reliance on the traditional disciplines of hospital based medicine, the apprenticeship nature of postgraduate learning, and the bias toward academic qualification for specialists too often resulted in doctors without the essential core knowledge for their area of practice and without the mental tools to translate it into direct benefit to the patient. The undergraduate curriculum has already been extensively revised. The training bodies of the royal colleges were planning wide ranging changes in their postgraduate training programmes when, in 1992, the European Commission (EC) initiated infraction proceedings against the UK on the grounds that the system of awarding specialist medical certification and the arrangements in place for mutual recognition of specialist qualifications between the UK and European partners did not comply with European law. A working group was set up under the chairmanship of the chief medical officer, Dr Kenneth Calman, with a brief to harmonise UK and European practice. The working group reported in April 1993. ${ }^{1}$ Their principal rec-
\end{abstract} ommendations were:

- That the colleges/faculties and postgraduate deans should implement their new training programmes by the end of 1995 and make arrangements to monitor the changes to ensure that standards were being maintained.

- That readiness for independent practice and eligibility for consultant appointment should be formalised by the award of an exit certificate, the UK certificate of completion of specialist training (CCST), and that this should have reciprocity with similar qualifications throughout the EC.

- That the current senior registrar and registrar grades should be combined into an integrated training grade and that average training time should come more into line with that in Europe.

Royal Victoria Infirmary, Newcastle upon Tyne D W A Milligan

Sheffield Children's Hospital D M B Hall

Correspondence to: Dr D W A Milligan, Ward 35, Leazes Wing, Royal Victoria Infirmary, Newcastle upon Tyne NE1 4LP.
Specialist training will be more focused and therefore shorter. A new specialist training grade (the specialist registrar) will replace the existing registrar and senior registrar grades. The entry requirements to the grade will be specified (as they are now) by a specialist advisory committee (SAC) in paediatrics, which is currently a subcommittee of the Joint Committee on Higher Medical Training. A minimum of two years of general professional training at senior house officer level is expected at the end of which MRCP(Paed) must be obtained in order to become a specialist registrar.

The minimum training period in the specialist registrar grade will be four years for general paediatrics and five years for those who wish to develop a specialty interest. Progress will be reviewed annually. There will be formal exit certification, the UK CCST. At the time of writing the NHS Executive takes the view that there should be only one CCST for paediatrics whatever specialty training has been undertaken. The CCST will be awarded by the new Special Training Authority. The British Paediatric Association (BPA) has only observer status on this group until it becomes a college.

The award of a CCST will entitle doctors to apply to the General Medical Council for inclusion on the specialist register. During the transition phase doctors who have been accredited by the SAC and those who are or have been consultants (but not locums) will have an automatic right for inclusion. Other doctors who will be eligible for inclusion are holders of an European economic area specialist certificate, non-European economic area specialists who are assessed to have appropriate training, and those with unorthodox or highly academic career posts so long as their training is assessed by the Special Training Authority as being equivalent to CCST standards. Inclusion on the specialist register confers the right to independent specialist practice and will become an essential prerequisite for consultant appointment from the beginning of 1997.

The new training programmes will place more emphasis on structured teaching and supervised learning and less on unsupervised experiential apprenticeship. Defining training programmes and maintaining standards will be the responsibility of the SAC, working in collaboration with the BPA. The responsibility for ensuring that training takes place lies with the postgraduate deans who will continue to hold $50 \%$ of the trainees' salaries $100 \%$ in Scotland). There will be regular appraisal and 
assessment, supervised by the deans and the SAC and mediated through regional advisors, BPA tutors, and local consultant mentors. An annual review between the specialist registrar and the dean provides information for the record of in-training assessment.

\section{What are the main effects?}

A reduction in higher specialist training time means that more trainees will be ready for consultant posts earlier. In order to accommodate this change there must therefore either be an increase in consultant numbers or a reduction in the number of trainees. Inherent in the Calman proposals is the notion that more patients should receive their care directly from consultants. In the short term, therefore, consultant numbers will need to rise.

The shorter training programmes, coupled with shorter working hours during training, ${ }^{2}$ will result in new consultants who are younger and less experienced at appointment. Exposure to individual clinical problems after appointment will be diluted by the larger consultant pool. The shorter period of generic training will require earlier decisions on a career pathway and there will be less flexibility for changes at a later stage. The parallel with the rest of Europe is not a comfortable one; most paediatricians in the EC practise office based primary care. The hope is that the more structured training will provide a more integrated knowledge base and the mindset for evidence based decision making. Consultants will work much more as teams, continuing education will become the norm, and junior consultants will continue to learn from, and be supported by, their more senior colleagues. It has been suggested that only some consultants will be identified as trainers and that they will have a contract which will have protected sessions for education which may be separately funded.

One of the consequences of producing more integrated training programmes is that much of the training will take place within the same deanery. While this will cause less disruption in family life and will be beneficial in terms of ease of organisation, it will decrease what many see to be one of the strengths of the current British training system, the ability for trainees to move to different training centres so that they are exposed to a broad range of opinion and experience. It will still be possible to move between deaneries but careful advance planning in consultation with the deans will be essential, particularly if the intended move is between England and Wales and Scotland or Northern Ireland which have their own separate numbering systems and training programmes.

Who makes the decisions on numbers?

There are two key bodies: the Specialist Workforce Advisory Group (SWAG) and the Advisory Group on Medical Education, Training and Staffing. SWAG deals with the mechanics of calculating the appropriate number of trainees for each specialty and takes over these functions from the Joint Planning Advisory Committee which has now been disbanded. The intention is that the adjustment of individual specialty numbers should be more flexible, more responsive to medium term changes, and based on more accurate data than has been hitherto available. The key source of data on trainees will be the postgraduate deans who are obliged to hold a common core dataset on each trainee and to make a planning and census return to NHS Executive once a year. Deans have recently completed a trawl of all potential specialist registrars within their deaneries and have made the first return of data. The NHS Executive are confident that this has given them an accurate picture of existing career registrars and senior registrars but acknowledge that there is still a problem with the reliable identification of doctors in research or who are currently overseas - the 'twilight zone'. The dataset and its handling is the responsibility of the Unified Training Grade Steering Group. The BPA has been involved in planning discussions together with other colleges and will have access to the relevant parts of the current deans' dataset at the end of 1995. SWAG will consult trusts about medium term (3-5 year) plans for consultant expansion in different specialties. Local Medical Workforce Advisory Groups will provide comment, including the implications for the new deal, on the plans of trusts in their 'patch' to the regional director.

The BPA is installing a new data system which will have fields that correspond to the deans' dataset so that information transfer should be reliable and simple. In the long term the deans' database should provide an accurate picture of numbers and distribution of doctors in the specialist registrar grade. During the transition the BPA proposes to monitor numbers in parallel in addition to collecting fresh baseline data on all doctors working in paediatrics and child health by means of a census based on 30 September 1995. In the long term the BPA database should not only be able to provide paediatric trainees with a forecast of consultant opportunities but also act as a useful recruitment tool as it is likely that most new graduates will be advised to train for the available market.

\section{What are the numbers for paediatrics?} In June 1995 the BPA submitted details of all existing career, visiting, and research registrars and senior registrars to SWAG together with an analysis of the predicted consultant workforce needed by the year 2000 and an estimation of the number of extra specialist registrars required to fill that number of consultant posts. Existing numbers were based on a 1994 update of the 1992 census. Projected consultant numbers were based on advice from specialty groups, ${ }^{3}$ from British Association for Community Child Health (BACCH), and from previous work on the optimum configuration of paediatric units. ${ }^{4}$ They took into account known retirements during that time 
and the extra input required from trainers after Calman implementation. Specialist registrar numbers were calculated using an average five year training time with allowances for research, part time working, and wastage.

SWAG (addressing the transition phase only) used an algorithm which assumes that the historical rate of consultant expansion is the most important determinant of future consultant numbers. Additional allowances are made for the proportion of service input lost from a reduction in the existing pool of trainees (the 'Calman factor'), the predicted retirement rate and loss to the specialty, and an assumption that average time between CCST and consultant appointment (the 'gap') will be six months. The number of additional trainees provisionally allocated on this basis was 786 , scaled down by two thirds to 262 for 1996/7.

\section{Are these numbers realistic?}

How do we find a large number of new specialist registrar recruits and who will fund their training? Neither question has yet been satisfactorily answered. Some changes will be revenue neutral but we would still need to find the people to fill the posts. It will be possible to replace visiting registrar posts with career posts once the current incumbents have completed their permit free training. We estimate that there are around 100 visiting posts which could eventually be transferred in this way if it was thought to be appropriate. A further intention is to translate as many senior senior house officer posts as possible into specialist registrar posts, though this may create problems with rotas and junior doctors' hours. There are about 300 such posts in paediatrics but, under the present rules, postholders will need to have passed the MRCP before they are eligible for an specialist registrar appointment. We hope to obtain the MRCP status of all current senior senior house officers in the forthcoming census. It may be possible to use some funds identified for the new deal in deaneries where the major issues of junior doctors' hours have been satisfactorily addressed. At the time of writing there is no undertaking that the government will fund the remaining posts. Even if the $50 \%$ of salaries held by the deans were funded the balance would have to be found by individual trusts.

\section{When is it all going to happen?}

The commissioning date of the specialist registrar grade nationally is 1 April 1996 although two specialities, surgery and radiology, started on 1 December 1995. Paediatrics and child health enters the fray on 1 October 1996 by which time we will need to fulfil the criteria laid down in the Guide to Specialist Registrar Training. ${ }^{5}$ These include transition arrangements; curricula, training programmes and training records ('logbooks'), approved by the SAC, for each specialty; planned rotations; and a mechanism for assessment. The transition phase will end when all potential specialist registrars have been identified and notified, when a mechanism for handling researchers who return after the end of transition (up to three years later) is in place, and when deans are in a position to begin recruiting to the grade on a competitive basis.

\section{What happens to existing registrars and senior registrars?}

Approved trainees will be allocated a national training number which is their passport to a training programme. Some senior registrars (we estimate around 50) will be eligible for a CCST as soon as the legislation is through. The remainder will automatically be allocated a national training number if they wish to enter the specialist registrar grade but they have the option of remaining on a senior registrar contract. Existing registrars who fulfil the minimum entry requirements to the specialist registrar grade will be assessed (under the aegis of the dean) for transfer to the specialist registrar grade. For most people there will be no difficulty but some, particularly those who have entered a research programme without formal interview for a registrar training post and those whose career progression is in doubt, will need a more thorough formal review. Flexible trainees will be treated in the same way. The quotas and points system have been abolished. Visiting registrars have the right to remain in their posts until the expiry of their permit free training.

Each programme will consist of a series of approved posts identified by a national post number. Posts themselves will be assessed for suitability for specialist registrar training on the basis of their proposed training content. The mechanism is likely to be through local structures in the interests of efficiency; the SAC will set standards and guidelines, but will only become directly involved in cases of dispute or real difficulty. It will be possible to move out of specialist registrar training to undertake research, or for other reasons, such as a period overseas, while retaining the national training number but specialist registrars should always take advice from their dean and regional adviser well in advance of committing themselves to such a move.

\section{Appointments and contracts}

There is new guidance on the constitution and function of the advisory appointments committees but any changes to the existing statutory instrument have to be ratified by parliament. The suggested changes include mandatory representation of the dean, structured references, and a range of improvements that reflect good employment practice in general. The appointment contract will usually be for 5.5 years. There may be a gap after the award of the CCST while the doctor seeks a consultant post. To cover this period the contract can be extended for a limited period by the dean. The length of the extension will be limited by availability of finance in the deanery concerned. It is not intended that this concession should be regarded as a means of extending specialty training; doctors who wish to 
acquire additional skills or expertise should normally seek to extend their specialist registrar training before they receive their CCST.

\section{The tasks ahead}

The two most urgent tasks are for specialty groups to publish detailed guidance on the minimum content of training programmes and for individual (groups of) trainers to define local core and subspecialty training programmes and submit them for approval to the regional adviser and dean who will need to fit them in to workable training rotations. Discussions with trusts about funding of at least $50 \%$ of any proposed new specialist registrar posts should take place without delay. The most important long term issue to be addressed is that of recruitment: how to make paediatrics more attractive as a career and to try and seize the advantage now of the recent $10 \%$ increase in medical school intake.

\section{Glossary}

Advisory Group on Medical Education, Training and Staffing (AGMETS) - Chaired by the chief medical officer; reports directly to the secretary of state. Responsible for England and Wales only. Equivalent body for Scotland is the Advisory Committee on Medical Establishments, and for Northern Ireland the Hospital Services Sub-Committee of the Central Advisory Medical Committee.

Calman factor - The decrease in service provision by specialist trainees resulting from shortening the training programme - for example, if training time falls from seven to five years service delivery will fall by $2 / 7$ ths (and will need to be replaced by consultant input).

Certificate of completion of specialist training (CCST) - Awarded by the Special Training Authority. Passport to independent specialist practice and eligibility for consultant appointment.

Continuing medical education - Came on stream for paediatrics on 1 January 1996.

Commissioning date - When the specialist registrar grade comes into being; 1 October 1996 for paediatrics and child health.

Deanery - The area of a dean's jurisdiction. Corresponds closely with old regions in most instances.

Deans' database - The source of information on all trainees. More accurately a dataset as all deans do not have the same software.

European economic area - European Economic Community countries together with some European Free Trace Association countries and Liechtenstein.

Gap - The time between award of CCST and consultant appointment. Average default assumed to be six months for transitional phase calculations.
FCHMT - Joint Committee (of the Royal College of Physicians) on Higher Medical Training.

Foint Planning Advisory Committee - Used to plan registrar and senior registrar numbers; now disbanded.

Local Medical Workforce Advisory Group Composed of members appointed by regional director to comment on trust plans for workforce planning. May eventually take over role of task forces. Still in discussion phase.

National programme or post number - Refers to a funded post approved for specialist registrar training by dean/regional adviser with or without the Specialist Advisory Committee (SAC). Issued by the dean. Similar structure to national training number.

National training number - Passport to a specialist registrar training programme. Retained by holder throughout training (even during time out) and, usually, until appointment as a consultant. Issued by postgraduate dean - for example NTH/002/374/V refers to visiting specialist registrar 374 in paediatrics (002) in the northern (NTH) deanery.

Paediatric SAC - One of several specialist advisory committees of the JCHMT which currently represents all of paediatrics.

Record of in-training assessment - A standardised system which deans will use to record the annual review of progress of individual specialist registrars. May be used to support recommendation of CCST award.

Specialist registrar - (was called higher specialist trainee).

Specialist training authority - Assesses training and awards CCST. Composed of college presidents and representatives from the General Medical Council, deans, and lay public.

Specialist Workforce Advisory Group Subcommittee of AGMETS. Chaired by $\mathrm{Dr}$ Graham Winyard (Medical Director, NHS Management Executive).

Transition phase - The time agreed nationally between NHS Management Executive and individual specialty between the specialty commissioning date and full implementation of the new arrangements.

Twilight zone - Registrars (or equivalent) who are currently in full time research (usually on soft money) and are not known to the system. Not thought to be a big problem in paediatrics.

Unified Training Grade Steering Group Oversees planning of information transfer.

\footnotetext{
Department of Health. Hospital doctors: training for the future. The report of the Working Group on Specialist Medical The report of the Working Group on Specialist

2 NHS Management Executive. Funior doctors' hours - the new deal. London: NHS Management Executive, 1991.

3 British Paediatric Association. Tertiary services for children and young people. London: BPA, 1995.

4 British Paediatric Association. Hospital paediatric medical staffing. London: BPA, 1993.

5 NHS Executive. Guide to specialist registrar training. London NHS Executive, 1995.
} 